\title{
ACERVOS DE PESQUISA: ESPAÇOS DE GERAÇÃO DE SENTIDO HISTÓRICO
}

\section{RESEARCH ARCHIVES: SPACES OF HISTORICAL SENSE GENERATION}

\author{
Mário Martins Viana Júnior* \\ Antonio Gilberto Ramos Nogueira**
}

\begin{abstract}
Resumo: Neste trabalho, buscamos apontar e refletir sobre algumas das possíveis experiências desenvolvidas por pesquisadores(as) nos espaços dos acervos de pesquisa no estado do Ceará. Para tanto, especificamente, problematizamos e indicamos formas de atuação docente no âmbito de iniciação e de formação dos(as) alunos(as) na dimensão da pesquisa, a partir de algumas experiências realizadas através da interação entre esta, o ensino e a extensão, agregando diferentes instituições. Neste sentido, o artigo não possui a pretensão de dar conta de um mapeamento geral dos acervos de pesquisa do Ceará. É, antes, uma reflexão sobre formas dinâmicas de geração de sentido histórico e de consciência histórica no trabalho entre ensino e pesquisa em alguns desses espaços.
\end{abstract}

Palavras-chave: Iniciação à pesquisa. Consciência histórica. Aprendizagem. Ceará.

* Professor Adjunto A do Departamento de História da Universidade Federal do Ceará (UFC), setor de estudos História do Brasil. E-mail: mario_ufc@hotmail.com

** Professor no Departamento de História e no Programa de Pós Graduaçao em História Social da Universidade Federal do Ceará (UFC). E-mail: antonioantonio@uol.com.br 


\begin{abstract}
In this paper we point and reflect on some of the possible experiments conducted by researchers in the areas of research archives in the state of Ceará. To this end, specifically, we problematize and indicate ways of teaching practice within students initiation and formation in research dimension, starting from some experiments conducted by interaction among research, teaching and extension, involving different institutions. In this sense, the article does not have the pretension to draw a general map of research archives in Ceará. It is rather a reflection on dynamic forms of historical sense and historical consciousness and of labor between teaching and research in some of these spaces.
\end{abstract}

Keywords: Scientific research initiation. Historical consciousness. Learning. Ceará.

O trabalho de iniciação à pesquisa histórica é um desafio constante para professores e discentes. Por um lado, não é difícil encontrar entre os profissionais ${ }^{1}$ a constatação de uma reduzida produção bibliográfica sobre práticas metodológicas e técnicas de pesquisa em história, o que muito provavelmente aponta para uma dificuldade inerente à própria disciplina, haja vista as especificidades dos seus objetos de pesquisa diante de outras ciências, tais como: a unicidade dos processos históricos, a observação indireta dos mesmos, a impossibilidade de reprodução e experimentação do vivido etc. ${ }^{2}$

Nesse sentido, é comum encontrarmos alunos(as) do curso de História, já em semestres avançados, que relatam ampla dificuldade no manejo e na análise documental, principalmente entre aqueles(as) que não participam de nenhum grupo de estudo ou que não têm acesso a bolsas como a do Programa Institucional de Bolsas de Iniciação Científica (PIBIC). Na disciplina de Métodos e Técnicas de Pesquisa Histórica II, por exemplo, ministrada por nós na Universidade Federal do Ceará (UFC), uma das queixas mais recorrentes foi a falta de discussão sobre as possibilidades de trabalho do método historiográfico, acompanhada da reclamação de que os(as) discentes são levados a fazer pesquisa pela simples observação daquelas já existentes. Ao nível da imitação e, portanto, de diminutas chances de ampliação e diversificação do fazer historiográfico, são poucas as intenções de pesquisas que conseguem alcançar um grau mais elevado de complexidade na graduação.

Por outro lado, a falta ou precária organização dos acervos de pesquisa sob a responsabilidade dos poderes públicos (estadual e municipal) foi identificada como uma constante no cotidiano dos estudantes de história e do historiador profissional cearense. ${ }^{3}$ De maneira geral, podemos sinalizar que a carência de investimentos na pasta da cultura está inserida em uma dinâmica maior de precarização dos equipamentos culturais relacionados diretamente ao métier do historiador e de outros profissionais que precisam desses equipamentos. 
Como exemplo, referimo-nos aos orçamentos do Governo do Estado do Ceará e da Prefeitura Municipal de Fortaleza em relação às suas secretarias de cultura: em 2013, dos R\$ 94 milhões destinados à SECULT/CE, apenas $56,36 \%$ foram gastos, enquanto que no nível municipal houve uma redução de $39 \%$ dos já baixos investimentos destinados à cultura para o ano de $2014 .{ }^{4} \mathrm{O}$ resultado destas ações pode ser visto no sucateamento de arquivos, bibliotecas, museus, entre outros espaços de pesquisa, que puseram em risco a preservação de milhares de documentos referentes à História do Ceará, além de comprometer o direito do cidadão à informação e à memória.

Nesse sentido, podemos destacar a difícil situação de dois importantes acervos cuja falta de tratamento ilustra o descaso para com a preservação documental. O primeiro deles diz respeito aos acervos dos antigos órgãos responsáveis pela organização e planejamento do Ceará, entre as décadas 1960-1990, tais como a Secretaria de Desenvolvimento Urbano e Meio Ambiente (SDU) e a Superintendência de Desenvolvimento Urbano do Estado do Ceará (SEDURB), extintas em 1999 para a criação da atual Secretaria de Infraestrutura (SEINFRA). É esta secretaria que hoje alberga tais acervos carentes de tratamento arquivístico, mas de grande potencial investigativo. A variedade documental, ainda não trabalhada pelos(as) historiadores(as), possui fontes como: mosaicos, fotografias aéreas, plantas, mapas cartográficos, estudos de impacto ambiental, análises de uso e ocupação do solo etc.

O segundo acervo é a documentação doada pela família Boris Frères. Os integrantes dessa família tiveram importante e singular atuação no cenário da economia e política cearense no século XIX. Segundo Denise Monteiro Takeya $^{5}$, a atuação dos Frères no Ceará repercutiu amplamente a expansão comercial francesa no Brasil, a partir dos anos de 1870, para a articulação de uma economia primário-exportadora às dinâmicas do mercado internacional, pautada no Ceará pela hegemonia da firma "Bóris Frères". Albergado no Arquivo Intermediário do Estado do Ceará, o acervo conta com farta documentação textual, manuscrita e impressa produzida em diferentes idiomas (português, francês, inglês, alemão), entre os anos de 1869 e 1969. Hoje, está dividida em 1.243 pacotes, 87 caixas e 222 livros, afora mapas e plantas que não possuem qualquer guia de consulta ao visitante.

Embora a maior parte da documentação esteja abrigada em condições satisfatórias, desde há muito é urgente o tratamento adequado de preservação, haja vista que os documentos encontram-se empacotados em papel madeira ou em sacos plásticos dificultando a sua conservação em virtude da falta de oxigenação. A ausência de tratamento arquivístico, inclusive, criou problemas irreversíveis como a perda e a deterioração de documentos que foram misturados a outras fontes e amontoados sem qualquer cuidado, conforme ilustração abaixo. 
Figura 1 - Acervo Boris Frères

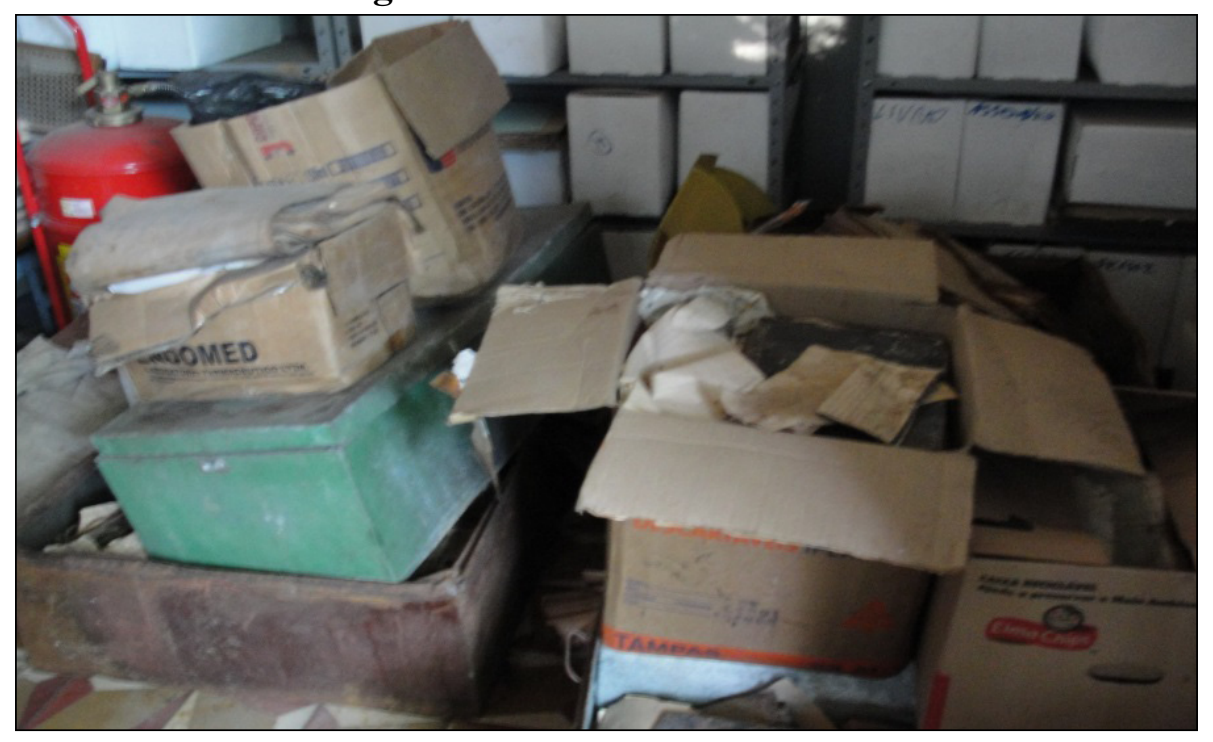

Fonte: Imagem produzida em março de 2013 no Arquivo Público Intermediário do Estado do Ceará

Mas a insensibilidade dos poderes públicos não fica restrita à dimensão da falta de conservação. Desdobra-se nas formas escolhidas para a manutenção dos acervos. Assim, no final de 2013 o Governo do Estado do Ceará ignorou o fato de inúmeros(as) pesquisadores(as) dependerem desses equipamentos culturais para as suas investigações e anunciou o fechamento concomitante para reformas da Academia Cearense de Letras (ACL), do Arquivo Público do Estado do Ceará (APEC), da Biblioteca Pública Menezes Pimentel (BPMP) e do Museu do Ceará. Tal ação mobilizou a organização de alunos(as) e demais pesquisadores(as) em torno do Movimento "Reformar SIM, fechar NÃO", o qual, contudo, não conseguiu sensibilizar a atenção governamental. ${ }^{6}$

Assim, pelo exposto, tanto no exercício da docência como nas atividades de pesquisador, constatamos que a atual conjuntura para a pesquisa histórica no Ceará possui sérios problemas e desafios que precisam ser enfrentados e discutidos em diversas dimensões (política, econômica, sociocultural) e campos (Arquivologia, Ciências da Informação, etc.).

Frente a esses obstáculos, buscamos apontar possibilidades de iniciação à pesquisa histórica, através de um duplo, mas imbricado, desafio: a reflexão sobre a importância do tratamento das fontes na formação do discente, em aproximação e em diálogo constante com os estudos sobre o ensino de História que tomam a "consciência histórica" como ferramenta heurística, tanto no sentido de descoberta, como no sentido de fomentação de processos de mudança para percepções mais dinâmicas da realidade que os sujeitos possam construir em relação ao tempo e ao espaço. São esses trabalhos, inclusive, que poderão atuar na alteração da própria escrita da história local. 


\section{A MEMÓRIA DOS ACERVOS DESLOCANDO A CONSCIÊNCIA HISTÓRICA}

Partimos de um ponto comum, básico, mas que consideramos fundamental: a necessidade de contato constante dos discentes com as fontes, isto é, de suas presenças permanentes nos espaços de pesquisa. E como tudo aquilo que a humanidade teve contato ou produziu pode ser utilizado como fonte no campo da historiografia, essa não é uma tarefa fácil e reduzida. Contudo, o que aqui nos interessa é justamente essa complexidade que confere riqueza ao trabalho dos(as) historiador(as) no contato com acervos, potencializando a diversidade de relações entre sujeitos pesquisadores(as) e objetos pesquisados.

Certamente, as formas de atuação planejadas pelo docente no contato com acervos significam um caminho profícuo para o estabelecimento das relações acima referidas, para a construção de caminhos alternativos às adversidades mencionadas e para consideráveis transformações na materialização das pesquisas em potencial e na escrita da história. Tal manejo delineado ocorre com o objetivo anterior de conferir maior complexidade ao "pensar historicamente" do discente, além de, na esteira das atividades refletidas e esquematizadas para inserção no âmbito da pesquisa, costurarmos objetivos maiores como o deslocamento do(a) aluno(a) das dimensões iniciais de descrição e de produção para os níveis e procedimentos de análise e de explicação.

Com isso, buscamos criar situações que impliquem os(as) futuros pesquisadores(as) na diversidade do trato documental com o interesse amplo e claro do desenvolvimento de competências e de habilidades que propiciem a autonomia na pesquisa histórica. Nesse sentido, a mera descrição das fontes, realizada, por exemplo, através de inventários descritivos, foi (re)significada aqui à luz do entendimento do discente sobre o processo de elaboração da fonte, das suas intenções e objetivos primeiros, da sua importância em determinado contexto histórico, do seu valor sociocultural, entre outros aspectos. Enfim, um primeiro contato guiado que possibilitará descobertas seguidas por "operações processuais" de crítica, análise e interpretação e que instigará o(a) jovem pesquisador(a) a se apropriar do método historiográfico para a produção de conhecimento. O caminho proposto é, portanto, aquele que parta das fontes, haja vista que:

Raras vezes uma pesquisa começa na teoria. O normal é que venha completar um determinado tipo de conhecimento, ou que apareçam novas documentações sobre algum assunto conhecido, ou que os próprios assuntos conhecidos mostrem sua concomitância com possíveis novos campos de pesquisa. Em mais de um caso, são os próprios problemas do presente que incitam uma pesquisa histórica. ${ }^{7}$ 
Não estamos negando o importante papel dos conhecimentos teóricos na formação discente. Sem eles, estudantes não conseguem se descolar das atividades de descrição e problematizar seus objetos de pesquisa. Entretanto, esse contato primeiro (e constante) com a fonte e o exercício inicial da descrição podem ser significados como partes fulcrais da pesquisa histórica. São eles que podem redimensionar, inclusive, o presente do discente, tempo elementar na reconstrução e problematização do passado, além de atuarem no processo de alteração das relações de significação. Nesse sentido, alterando o presente do(a) aluno(a), estamos incitando a modificação de suas próprias formas de atribuir significados ao mundo, alterando sua percepção do passado, sua concepção sobre o tempo e sobre a pesquisa e sua relação com os acervos históricos. Enfim, estamos interferindo diretamente na sua aprendizagem como futuro(a) historiador(a).

O foco deste trabalho pode ser assinalado também como a busca pelo desenvolvimento da "consciência histórica" ${ }^{8}$ dos(as) discentes, mediante, sobretudo, a dilatação e o alargamento das concepções temporais atingidas no contato orientado com as fontes. Nesse contexto, inclusive, a proximidade com os documentos toma proporções maiores em virtude da ampliação dos conhecimentos sobre as práticas metodológicas e as técnicas de pesquisa historiográfica postas em destaque no exercício da pesquisa. E é por meio dessas ações, que modificam a consciência histórica, que se abre a possibilidade de alteração da própria organização sociocultural atual e, acrescentaríamos, dos acervos e das fontes de pesquisa em uma reinterpretação constante sobre o passado.

\begin{abstract}
Segundo Agnes Heller, a perspectiva de desenvolvimento da consciência histórica ao longo do tempo pode ser descrita, entre outras formas, como um processo de ampliação do tempo que se pode conceber, e cuja representação interfere nas formas de organização social [...]. Ao agir, o ser humano já se pauta por um passado que se oferece a ser lembrado e considerado sem mediação da narrativa, antes do trabalho interpretativo da consciência histórica; um conjunto em que "o passado não é consciente como passado, mas vale como presente puro e simples, na atemporalidade do óbvio". ${ }^{9}$
\end{abstract}

Assim, acreditamos que o trabalho de ensino e pesquisa se amalgama no sentido de ressignificação constante das instituições e de alteração da consciência histórica dos discentes através de suas atuações nos acervos. Estes deixam de ser entendidos como simples esteiras de perpetuação das tradições no presente e passam a ser identificados, descritos e problematizados como lócus de reinterpretação do passado e do presente. Em concomitância e após a etapa primeira de estranhamento e descrição dos documentos 
contidos nos acervos, observamos que a alteração da consciência histórica dos(as) jovens pesquisadores(as) se expressou na própria transformação da relação com o passado: em vez de reproduzido e perpetuado acriticamente, o passado, ou melhor, as relações estabelecidas em tempos pretéritos passaram a ser observadas sob a dimensão analítica e interpretativa. Vejamos algumas experiências dessas proposições.

\section{ALTERANDO A RELAÇÃO COM O PASSADO E COM OS REGISTROS DO PASSADO}

No Ceará, algumas das experiências mais bem sucedidas de inserção dos discentes na atividade de pesquisa ocorreram em decorrência da concretização de projetos de pesquisa e de extensão em diferentes níveis e frentes. Não sem dificuldades, o elemento fundamental dessas atividades foi a sensibilização de docentes e discentes no âmbito acadêmico, além dos diretores dos espaços onde estão salvaguardados os acervos. Das parcerias e convênios, resultaram trabalhos de ampla e variada repercussão com consequências salutares para academia e sociedade.

Para efeito de organização e descrição das possibilidades de atividades de pesquisa, pudemos observar pelo menos três grandes níveis e formas de atuação resultantes da parceria entre as instituições, que assim denominaremos: descritivo e organizativo; descritivo; e produtivo-organizativo. Para cada dimensão destas formas de trabalho houve uma preparação, um direcionamento, uma discussão bibliográfica específica, enfim, uma reflexão sobre modos de saber-fazer em relação às práticas metodológicas historiográficas. O estabelecimento de problemas, de procedimentos para a resolução destes, a elaboração de ferramentas para apreensão da realidade e a constituição de relações entre método e técnicas foram alguns dos elementos postos em exercício na formação dos discentes. Destaquemos, então, apenas algumas dessas experiências para dar mais concretude à proposta deste artigo.

I - No nível descritivo-organizativo são interessantíssimos os trabalhos desenvolvidos pela Universidade Federal do Ceará em parceria com o Arquivo Público do Estado do Ceará (APEC) visando o tratamento, a preservação e a organização de acervos. Através do Programa de Educação Tutorial do curso de História (PET/História), mediante as iniciativas das professoras Verônica Secreto, Edilene Toledo e do professor Franck Pierre Ribard, a UFC motivou dezenas de alunos(as) bolsistas e não bolsistas na identificação, catalogação e organização de um enorme acervo pertencente ao poder judiciário e sob a tutela do APEC.

Com o objetivo de captar, preservar e organizar fontes relacionadas ao Ceará desde o período colonial até a República, o APEC conta hoje com ampla 
e diversa documentação, como correspondências, processos, relatórios, censos, certidões, inventários, escrituras, mapas, plantas, entre outros oriundos dos Poderes Executivo, Legislativo, Judiciário (Extra-Judiciário) e, também, de cunho particular. Contudo, embora o APEC possua hoje mais de 30 índices e guias diferentes ${ }^{10}$, como o Guia da Instrução Pública 1833-1889, que assinala a existência de mais de 32.000 documentos distintos, além de contar com uma parte pequena do acervo digitalizada, o universo arquivístico da instituição põe em evidência a dificuldade do poder estatal na organização e preservação dos inúmeros documentos, conforme referido acima.

Nesse sentido, as parcerias entre instituições surgem como possibilidades riquíssimas, não para dar conta de atribuições do estado, mas como possibilidade de aprendizagem conjunta na iniciação à pesquisa e aos acervos. Assim, o projeto "Preservar para conservar, conservar para conhecer: a história nos processos criminais em Fortaleza", capitaneado pelo PET/História entre os anos de 2003 e 2006, conseguiu identificar, organizar, catalogar e recondicionar 2.587 processos-crime produzidos entre os anos de 1910 e 1950, que estavam em precárias condições de conservação e acesso.

Para reintegração ao Fundo do Tribunal de Justiça, os processos passaram antes por uma fase de identificação, triagem e recondicionamento em pastas de cartolina e caixas de arquivo. Concomitante a essa atividade no APEC, os(as) integrantes da pesquisa realizaram ampla discussão bibliográfica referente a fontes criminais, o que ampliou o pensar histórico, além de permitir um olhar mais crítico sobre os documentos. A apropriação destes se deu também pela atividade de construção conjunta de fichas de catalogação realizada pelo grupo. Chamados à reflexão, docentes e discentes debateram e identificaram pontos fulcrais nos processos para a organização do acervo, tais como: fundo, série, subsérie, caixa, número do processo, local, ano, tribunal, autor, ação, réu, vítima, palavras-chave e resumo do processo.

Assim, depois de identificados e realocados na Série Ações Criminais, tais documentos foram descritos, analisados e resumidos pelos(as) pesquisadores(as) no sentido de propor uma organização que facilitasse a consulta e o acesso. O trabalho conjunto permitiu, então, o agrupamento dos processos em temáticas específicas que geraram uma divisão de 14 subséries: Ferimentos; Homicídios; Crimes de Trânsito; Crimes contra a Propriedade; Crimes Políticos; Extorsão e Estelionato; Contravenções; Injúrias e Calúnias; Desordens; Crimes de Sedução e Defloramento; Crimes Sexuais; Incêndios; Despejos; Cobranças de Dívidas; Ofícios Diversos. Toda a inventariação dos processos foi reunida em um Guia de Fontes disponibilizado no APEC.

Mas o trabalho em conjunto extrapolou a dimensão descritiva e organizativa e cumpriu um importante papel na formação dos(as) envolvidos(as). O livro A História em processo: ações criminais em Fortaleza (1910-1950) reuniu artigos dos(as) integrantes do projeto e foi um dos produtos obtidos com 
o término do trabalho, projetando na cena local algumas das amplas e diversas possibilidades de pesquisa com a utilização dos processos-crime:

A partir desse trabalho coletivo, cada jovem pesquisador debruçou-se sobre um ou mais processos, analisando mais profundamente uma determinada problemática entre as muitas que a documentação apresentava. São esses exercícios de pesquisa e elaboração de resultados, realizados por vários alunos do curso de história que participam do projeto, que apresentamos aqui, além dos textos escritos por nós, professores responsáveis pelo projeto, que trazem considerações gerais sobre as potencialidades do uso de fontes criminais para a construção do conhecimento histórico. ${ }^{11}$

O contato com uma enorme variedade de fontes dilatou as possibilidades de pesquisa não apenas do grupo envolvido. Ao disponibilizar por meio de fácil acesso a consulta aos milhares de processos-crime, que ajudam a desvelar o cotidiano, os hábitos, os costumes, os conflitos dos fortalezenses durante a primeira metade do século XX, alterou-se significativamente a atenção e o rumo das pesquisas de alguns dos(as) historiadores(as) nos anos subsequentes à publicação do guia de fontes.

Para termos uma ideia do impacto dessa ação conjunta e planejada, apresentamos um levantamento das dissertações defendidas no Programa de Pós Graduação em História da UFC. Do ano de 2000, data de início das atividades do Mestrado em História da UFC, até 2006, ano de conclusão do Guia de Fontes, apenas dois trabalhos fizeram uso dos processos-crime como fonte. Contudo, entre 2007-2013, esse número subiu para 10 (dez) trabalhos, significando um aumento de $500 \%$. A tabela abaixo ajuda a visualizar melhor a importância que os documentos criminais foram ganhando no Programa de Pós-Graduação (PPG).

Tabela 1 - Dissertações do PPG em História/UFC (2007-2013)

\begin{tabular}{cccc}
\hline ANO & $\begin{array}{c}\text { TOTAL DE } \\
\text { DISSERTAÇOEES }\end{array}$ & $\begin{array}{c}\text { DISSERTAÇÕES COM } \\
\text { FONTES CRIMINAIS }\end{array}$ & $\begin{array}{c}\text { PERCENTUAL } \\
\text { PROPORCIONAL }\end{array}$ \\
\hline 2007 & 18 & 3 & $17 \%$ \\
2008 & 19 & 1 & $5,3 \%$ \\
2009 & 13 & 4 & $31 \%$ \\
2010 & 16 & 1 & $6,25 \%$ \\
2011 & 15 & 2 & $13,4 \%$ \\
2012 & 12 & 0 & 0 \\
\hline
\end{tabular}

Fonte: Secretaria do Programa de Pós-Graduação em História/UFC. 
Destacam-se aí os trabalhos dissertativos de alguns dos ex-petianos(as) que fizeram largo uso das fontes criminais para o aprofundamento de seus estudos, tais como: Carlos Henrique Moura Barbosa, Eduardo Oliveira Parente, Idalina Freitas, Mário Martins Viana Júnior, Marla de Albuquerque Atayde, Márcio Inácio da Silva, Raimundo Hélio Lopes e Rubem Maciel. Temáticas como o carnaval, relações de gênero, cinema, cotidiano urbano, operariado, migração, entre outras, foram aventadas a partir dos conflitos que resultaram em processos-crime. Materializadores dos registros das contendas em tempos pretéritos, os processos acabaram gerando contendas e debates acadêmicos ao serem apropriados como fontes históricas no tempo presente daqueles(as) historiadores(as).

É importante assinalarmos que a ausência do uso de fontes nos trabalhos dissertativos nos anos 2012 e 2013 não deve ser relacionada diretamente a pouca atenção conferida pelos(as) pesquisadores(as) a este tipo de documentação. Antes, observamos que houve uma alteração substancial na atenção sobre o recorte temporal e espacial dos objetos de pesquisa. Dessa maneira, enquanto em 2012 apenas dois trabalhos referenciaram temas relacionados à cidade de Fortaleza dos anos de 1910-1950 (período e espaço possíveis de serem observados pelos processos criminais), em 2013 nenhuma pesquisa se deteve a esse recorte, conferindo, portanto, inviabilidade ao uso desse material.

Mas o que queremos apontar a partir da Tabela 1 são outras questões que impactaram diretamente na experiência de pesquisa das pessoas envolvidas no trabalho. Levados ao exercício inicial de descrição e organização, os estudantes tiveram suas concepções de tempo e espaço dilatadas, alterando suas consciências históricas para uma forma de pensar de tipo mais observadora, problematizadora e crítica dentro de um processo de aprendizagem mais amplo e em contato direto com o acervo e com balizas teóricas construídas pelo grupo. Ademais, esse avanço no tratamento das fontes criminais possibilitou uma alteração na própria organização da produção do conhecimento no PPG em História da UFC, tendo em conta a posição crucial que esses documentos passaram a ter na interpretação histórica dos(as) pesquisadores(as).

Nessa experiência, a atividade descritiva e organizativa foi ampliada e tomou formas de pesquisa histórica, aqui entendida como expressada por Jorn Rusen:

[...] um processo cognitivo, no qual os dados das fontes são apreendidos e elaborados para concretizar ou modificar empiricamente perspectivas (teóricas) referentes ao passado humano. [...] A pesquisa é o passo metodicamente regulado, e por isso intersubjetivamente controlável, das respostas possíveis às reais. Ela apreende a informação das fontes à luz de perspectivas teóricas previamente elaboradas, e elabora a informação apreendida sob perspectivas, para 
que se realizem empiricamente em histórias com conteúdo efetivo. ${ }^{12}$

Assim, além da interferência na relação dos sujeitos com o passado, o projeto desenvolvido pelo PET-História/UFC mostrou a viabilidade de uma intervenção nas relações dos sujeitos com os registros do passado, ampliando e dando visibilidade a estes, e influenciando singularmente não apenas nos rumos e sentidos das pesquisas, mas também na escrita da história no Ceará. Em suma, a pesquisa empírica descritiva e organizativa de um acervo no APEC, acompanhada de discussão bibliográfica específica, estimulou o surgimento de pesquisas analíticas, temáticas, qualitativas, quantitativas e muito contribui para algumas mudanças nos rumos da reflexão e da historiografia local.

II - No nível descritivo, chamamos atenção para a continuidade de parceria entre UFC e APEC, via PET-História/UFC, através do projeto "Guia de Fontes para a História da Escravidão no Ceará". Iniciado em 2006 e finalizado em 2012, sob as tutorias dos professores Franck P. Ribard, Almir Leal de Oliveira, Antonio Gilberto Ramos Nogueira e Mário Martins Viana Jr., tal projeto possibilitou o mapeamento de fontes diretamente relacionadas à temática da escravidão no Ceará, sobretudo, na segunda metade do século XIX. Assim, foram inventariados dez livros de procurações e escrituras de compra e venda de escravos, realizadas na província do Ceará e concentradas principalmente na década de 1870 .

O trabalho coletivo foi planejado e divido em sete grandes etapas: levantamento, identificação e mapeamento inicial do corpo documental; higienização e acondicionamento das fontes; introdução à paleografia; pesquisa sobre as principais informações contidas nos documentos; reflexão sobre as informações encontradas e elaboração de fichas/resumo; catalogação dos livros; sistematização e publicação de um guia de fontes. Concomitante a estas etapas de trabalho, foram realizadas discussões bibliográficas referentes à temática da escravidão no Brasil que se integraram aos objetivos maiores do projeto, identificados como: capacitar discentes na escrita paleográfica, ampliar sua percepção crítica acerca dos documentos produzidos no século XIX, buscar problematizar aspectos que pudessem suscitar investigações individuais futuras e conferir visibilidade ao tema da escravidão no Ceará através de um guia que facilitasse o acesso aos documentos.

Das discussões em grupo sobre as fontes e a bibliografia surgiram, então, propostas riquíssimas acerca da composição das fichas para a apreensão das informações consideradas mais importantes. A diferenciação primeira entre tipo de fonte e conteúdo do documento permitiu que os estudantes construíssem campos de identificação específicos. Assim, foram destacados os seguintes itens: livro, $\mathrm{n}^{\circ}$ da escritura no livro, folhas, natureza do registro, data, local, identificação e qualificação dos envolvidos na negociação (escravo, vendedor, 
procurador, comprador), quantia da transação, transcrição integral do cabeçalho, matrícula do escravo, assinaturas constantes, tabelião, valor do selo, impostos e informações adicionais.

Infelizmente, o tratamento dessa documentação não gerou grande sensibilização entre os(as) integrantes da pesquisa para que realizassem análises qualitativas sobre tais fontes, ficando essa atividade restrita ao âmbito dos relatórios de pesquisa. Muito provavelmente as mudanças de tutoria, portanto, de orientação das pesquisas do grupo, e o rodízio de bolsistas, acrescidos da dificuldade de captação de recursos para publicação do catálogo que se encontra finalizado, mas não publicitado, criaram empecilhos no desenvolvimento de análises posteriores à catalogação. Exceto pelo estudo dissertativo da ex-bolsista Mariana de Oliveira Sousa, que problematiza a precoce abolição no Ceará em relação a outras províncias do Império, nenhum outro participante se motivou a trabalhar com as fontes cartoriais em torno do tema da escravidão. ${ }^{13}$

Entretanto, isso não denota uma baixa importância da documentação tratada. Em nossa análise, trata-se antes de uma falha no planejamento da equipe que não contemplou a produção na dimensão analítica por parte dos discentes através da atividade escrita, em um contexto em que os estudos sobre escravidão no Ceará ainda são diminutos. Ademais, o estreito recorte temporal dos documentos, a autonomia dos(as) bolsistas na escolha de suas pesquisas e a exclusividade de um único tipo de fonte existente nos livros tratados parecem ter contribuído para a manutenção da carência de estudos mais aprofundados na área, o que não implica que essa atividade de catalogação não tenha contribuído para a dilatação das percepções temporais e espaciais no pensar historicamente dos envolvidos.

As 1.723 escrituras diversas que envolvem atividades de compra e de venda, procuração, hipoteca, empréstimo, doação, entre outras negociações, são elementos riquíssimos para pensarmos a dinâmica das relações em torno do universo escravagista na província do Ceará, primeira a abolir a escravidão no Brasil (1884). Nelas constam informações que talvez permitam elucidar melhor as peculiaridades desse pioneirismo, além de outras proposições, tais como: origem e etnia dos escravos, faixa etária, caracterização dos seus ofícios, composições familiares, estratégias de solidariedade, conflitos, questões de gênero, estratégias de compra e venda, alianças estabelecidas entre os senhores, trajetórias e locomoções realizadas, dimensão da valorização/desvalorização pecuniária dos bens moventes e semoventes, emigração e imigração, entre muitas outras.

A título de ilustração sobre as possibilidades de pesquisa, assinalamos o mapeamento do conjunto de ações realizadas por Joaquim Álvaro Garcia no Ceará, entre fevereiro e abril de 1878 . Nesse período, o comerciante de cativos dispôs a elevada quantia de 8:760\$000 para a compra de 15 escravos em seu próprio nome. Desvelando uma dinâmica mais ampla, as negociações 
desse sujeito apontaram para a intensidade do tráfico interprovincial com a participação de cativos oriundos de diferentes partes do Ceará (Cachoeira, Canindé, Baturité, Quixeramobim e São Francisco), e que entravam na Capital pela ação dos procuradores. Havendo certo nivelamento quanto ao sexo, com ligeira superioridade numérica dos homens, a maior disparidade entre os(as) cativos(as) ocorria principalmente em relação à idade, com a preferência da compra em quase $70 \%$ dos casos por escravos(as) com idade inferior aos 20 anos. A juventude, que poderia significar força e altivez, era uma engrenagem do tráfico interprovincial.

Essas, aliás, eram as preferências percentuais de outro conjunto de atividades feitas por Joaquim Garcia a pedido do comendador do Rio de Janeiro, Francisco Coelho da Fonseca Júnior. Atuando como procurador deste, em três meses, Joaquim comprou dez escravos movimentando outros pomposos 8:500\$000. A diferença básica estava na superioridade de $80 \%$ de cativos serem oriundos de localidades do interior da província (4 de Limoeiro, 1 de Jacutinga, 1 de Morada Nova, 1 de São João do Príncipe e 1 de Arneiróz) e apenas 20\% de Fortaleza. Adquiridos em praça fortalezense, os(as) escravos(as) deveriam seguir viagem para o Rio de Janeiro.

Intensificando o tráfico interprovincial, as negociações mostravam ainda formas de ligação entre pontos extremamente distantes do Império, como Rio de Janeiro e Limoeiro do Norte, além de desvelar a atuação dos principais sujeitos praticantes desse comércio. Indivíduos que paulatinamente foram "branqueando" seus capitais à medida que o comércio de cativos foi dando sinais de enfraquecimento.

\begin{abstract}
Alguns dos ricos proprietários e proprietárias do século $\mathrm{XX}$, inclusive, tinham feito fortuna com a exploração do trabalho cativo. Como exemplo, podemos citar o caso de Joaquim da Cunha Freire, o Barão da Ibiapaba. Além de importante comerciante de imóveis na Capital, esse senhor se destacou por suas empreitadas do tráfico interprovincial de cativos sendo dono de uma das maiores firmas de negócio de escravos no Ceará. Ao falecer, deixou uma enorme fortuna em dinheiro e bens para a sua esposa Maria Eugenia dos Santos que, como Baronesa de Ibiapaba, participou do comércio de venda e compra de terras em Fortaleza, destacando-se como "senhorio direto" de vários terrenos, cobrando foros perpétuos $[\ldots] .{ }^{14}$
\end{abstract}

Seriam essas características quanto às negociações e aos perfis dos(as) negociados(as) (origem, idade, sexo) tendências pertencentes apenas a esse período? O que elas representam? O que significava, por exemplo, o baixo valor (350\$000) de uma família de três escravos adquirida por Joaquim Garcia? ${ }^{15}$ 
Existiram outras famílias negociadas e registradas nesses documentos? Quais as suas formas de composição? Quais os ofícios desses cativos? Como se relacionavam? Quais os outros sujeitos que alimentavam e participavam dessa travessia de escravos dentro do Império? Enfim, esses são apenas alguns dos múltiplos problemas que podem ser lançados para e a partir dessas fontes e que ainda necessitam de investigações mais aprofundadas. Problemas estes que surgiram, inclusive, no e do debate realizado pelos envolvidos no trabalho. Certamente, a publicitação do guia será um importante estímulo na direção de propostas resolutivas, mas a ausência de análises concretas põe em evidência um problema que localizamos, principalmente, no planejamento da ação.

Ainda no nível descritivo, outro importante trabalho que podemos assinalar diz respeito àquele realizado no âmbito da Coordenadoria de Patrimônio Histórico e Cultural, subordinada à Secretaria de Cultura de Fortaleza (SECULTFOR). Diferentemente dos outros dois exercícios de pesquisa que contaram com a participação de bolsistas remunerados pelo Programa de Educação Tutorial (PET/História), o referido trabalho foi desenvolvido dentro da disciplina da Atividade de Estágio Supervisionado I, através de convênio estabelecido entre a UFC e a Prefeitura Municipal de Fortaleza.

Embora houvesse o foco na preparação prática de estudantes de bacharelado fora do âmbito escolar, com o intuito de inseri-los na atividade profissional, tratava-se de uma proposta de incentivo à pesquisa diferenciada por não contar com grupo estruturado e por não implicar remuneração direta. Entretanto, foram justamente essas peculiaridades que permitiram uma leitura mais ampla sobre as possibilidades de atuação docente/discente. Ao incentivar os(as) alunos(as) ao voluntarismo e ao espírito de coletividade, os professores apontaram possiblidades de trabalho não necessariamente circunscritas ao ganho material. Não que as bolsas remuneradas sejam desprezíveis. Isso significa, antes, iniciativas e voluntarismos paralelos possíveis que ampliam a ação acadêmica em interlocução com a sociedade. Destarte, amplia a percepção do discente sobre o presente em que está inserido e torna possível seu contato de forma orientada com acervos de pesquisa.

Especificamente, o objetivo central da atividade, em consonância com a iniciação dos(as) alunos(as) no âmbito da pesquisa, foi o de identificar toda a documentação referente aos processos de tombamento dos bens elevados à condição de patrimônio histórico-cultural e natural no município de Fortaleza. Nesse sentido, após negociação e contato positivo, a Coordenadoria de Patrimônio ofertou como contrapartida da ação a iniciação dos(as) alunos(as) na temática da arquivística e do patrimônio, através de oficinas que sinalizaram a forma de proceder dos integrantes da disciplina no manejo dos documentos.

Diferentemente dos exercícios assinalados acima, não houve contato prévio com as fontes e não aconteceram as etapas de discussão bibliográfica específica e de elaboração de ficha de pesquisa de forma conjunta pelos 
partícipes do estágio. Nos termos assumidos no convênio, e diante do curto tempo da disciplina de Estágio para dar conta da ampla variedade de fontes existentes em cada um dos mais de cinquenta processos de tombamento, essa metodologia tornou-se a mais viável para a consecução dos trabalhos, embora não fosse a mais profícua, tendo em vista a anulação de etapas importantes do exercício de pesquisa e de reflexão que seriam realizadas pelos próprios discentes.

Deslocados(as) da dimensão de construção coletiva das diretrizes da pesquisa, os(as) discentes foram introduzidos no conjunto de princípios e técnicas nos âmbitos da produção, organização, guarda, preservação e uso de documentos do acervo da SECULTFOR. Ademais, aprenderam noções gerais sobre o patrimônio local, com foco específico para as etapas dos processos de tombamento e os documentos necessários para a sua execução, tais como os iniciais sinalizados pela Lei 9.347/2008:

Art. 10-As propostas de tombamento, encaminhadas pelos proprietários ou por terceiros interessados, deverão conter: I - descrição e exata caracterização do bem respectivo; II endereço do bem, se imóvel, ou do local onde se encontra, se móvel; III - delimitação da área objeto da proposta, quando conjunto urbano, sítio ou paisagem natural; IV - nome e endereço do proprietário do bem respectivo, salvo quando se tratar de conjunto urbano, cidade, vila ou povoado; V nome completo e endereço do proponente e menção de ser ou não proprietário do bem; VI - documentos relativos ao bem, incluídos fotografias ou cartografia; VII - justificativa do pedido. ${ }^{16}$

O olhar por dentro sobre a configuração dos processos de tombamento e o melhor entendimento acerca de suas fases de elaboração/execução colocou em relevo uma série de documentos inéditos no âmbito da pesquisa e escrita da história local. Os(as) pesquisadores(as) tomaram conhecimento, por exemplo, que após a (i) recepção e abertura do processo na SECULTFOR gera-se (ii) uma notificação ao proprietário do bem objeto de tombamento, abrindo-se um período para a (iii) anuência ou impugnação da ação, seguida por (iv) uma etapa de estudos e emissão de pareceres até a (v) a publicação da instrução normativa sobre o tombamento do bem.

Para além da simples burocracia da institucionalização do processo, cada etapa possibilitou uma infinidade de documentos descobertos e inventariados pelos(as) estudantes, que variaram desde a complexa caracterização dos bens tombáveis com textos escritos, imagens, mapas, plantas arquitetônicas, notícias de jornais, revistas, entre outros, até às argumentações legalistas para a impugnação e o posicionamento da Prefeitura diante dos debates. Dessa maneira, 
os(as) alunos(as) tiveram contato com uma dimensão extremamente conflitiva no âmbito histórico e cultural local, o que viabilizou uma ressignificação dos bens, espaços e culturas que compõem a sua dinâmica cotidiana, além de ampliar o entendimento sobre os debates que atuam na construção da cidade em que vivem, expressos em discursos que, portanto, atuam na construção de suas próprias relações. Desse exercício surgiram, por exemplo, apontamentos de como pensar o patrimônio como um processo de seleção e atribuições de valores relacionados à escrita da história.

O trabalho de inventariar descritivamente os documentos garantiu não apenas o acesso mais rápido e seguro às informações sobre o patrimônio local, mas reconfigurou o próprio significado e funcionalidade do acervo da SECULTFOR. O conjunto de documentos sobre bens tombados era majoritariamente utilizado pelos servidores para fins burocráticos ou para consultas externas por advogados, principalmente com fins legalistas. Com a intervenção dos(as) discentes, o espaço passou a ter uma atmosfera diferenciada ao atender um público de pesquisadores(as) mais amplo e diverso, abrindo a chance de transformação das informações inventariadas em outros produtos culturais, como guias, exposições, materiais didáticos voltados para educação patrimonial, análises acadêmicas, entre outros.

Dessa maneira, se, por um lado, é possível observar a ação do(a) historiador(a) profissional imersa em práticas metodológicas, procedimentos e técnicas que abordam os tempos pretéritos através de fragmentos e indícios que viabilizam a construção de narrativas interpretativas e explicativas ${ }^{17}$, por outro lado, afirmamos a necessidade e viabilidade de lançarmos olhar e intervirmos nos processos de profissionalização anterior com foco na importância e dinâmica possibilitada pelo contato com os acervos de pesquisa.

Assim, além do movimento profissional que toma o indício como referência e leva à construção da narrativa, foi possível evidenciar e assinalar outro, anterior e não menos importante, que conduz à identificação e à construção do mesmo indício: evidência que passa a ser observada e (re)significada pelo(a) orientando(a) como um fragmento para análise do tempo pretérito e do tempo presente e não mais como um simples suporte institucional-burocrático.

O objetivo maior da atividade era fazer com que os participantes do processo de inventariação não ficassem detidos apenas à fase descritiva. No deslocar das dimensões temporais e espaciais, no ampliar da reflexão sobre as formas distintas de atribuição de sentido e no estímulo a uma forma de pensar historicamente mais próxima de uma consciência histórica crítica e problematizadora, a partir do contato com acervos, os(as) discentes tiveram suas experiências alargadas no âmbito da iniciação profissional. Em alguns segmentos, inclusive, foram convidados(as) a extrapolarem a dimensão descritiva, organizativa e analítica para atuarem no nível produtivo de fontes, conforme veremos a seguir. 
III - No nível produtivo-organizativo, podemos situar os trabalhos que têm se utilizado da metodologia da história oral para a constituição de acervos de memória e preservação do patrimônio cultural. Nesse exercício, vale destacar o Projeto Memórias, Narrativas e Saberes Tradicionais da Comunidade de Ponta Grossa - Icapuí (CE), desenvolvido no âmbito do PET e o Projeto Patrimônio e História Local: Inventário de Referências Culturais do Bairro do Benfica Fortaleza (CE), elaborado no interior das atividades do Grupo de Estudos e Pesquisas em Patrimônio e Memória - GEPPM/UFC/CNPQ. ${ }^{18}$

Ambos os projetos figuram como demandas e representações de um movimento crescente em que o patrimônio e a memória se constituem em conceitos-chaves da experiência temporal da sociedade contemporânea. No Ceará, e nas sociedades ocidentais de forma mais ampla, os trabalhos da memória e a temática do patrimônio vêm ganhando espaço em virtude do desejo cada vez maior de transformarmos o nosso passado em patrimônio cultural.

Assim, se, por um lado, nos deslocamentos da memória ela se tornou plural revelando outras vozes, narrativas e temporalidades em oposição à memória nacional, por outro lado a noção ampla e plural de patrimônio, abarcando as manifestações tangíveis e intangíveis, consagradas e não consagradas, conforma um tempo social que busca incorporar a produção dos segmentos sociais em sua diversidade cultural. Operando um novo regime de historicidade $^{19}$, ela se define e se constitui em perspectiva com as relações que estabelecemos com o passado, o presente e o futuro. ${ }^{20}$

O sentido do patrimônio, entendido como signo de cultura, tem sua função intimamente associada à formação dos grupos de identidade e à constituição de práticas que forjam laços referenciais dos grupos na sua (auto) afirmação. Na sua mediação com a memória, o campo do patrimônio cultural vem se constituindo em nova perspectiva de abordagem para a história e os historiadores. Seja como objeto da pesquisa histórica, como possibilidade de intervenção ou ainda inserido nas temáticas transversais contempladas nos PCNs, os historiadores têm sido convocados a enfrentar os novos desafios da pesquisa acadêmica ante os saberes, os fazeres, as expressões culturais, as oralidades, as memórias das comunidades tradicionais e suas representações, bem como a observação da aprendizagem discente decorrente dos processos e projetos de pesquisa envoltos nesses aspectos e temáticas.

Como exemplo desse enfrentamento, citamos o projeto "Memórias e Narrativas da Comunidade Tradicional de Ponta Grossa", desenvolvido no período de nossa experiência de tutoria no PET/História entre os anos de $2010 \mathrm{e}$ 2012. A singularidade desse projeto foi pautada por um exercício de construção metodológica que buscou aliar a Etnografia/Antropologia Social e a história oral. Nesse exercício, o trabalho de campo, valendo-se de tais metodologias, foi o seu diferencial. Aí, os 12 bolsistas puderam aguçar suas sensibilidades e construir coletivamente uma metodologia de registro com vistas à preservação da memória e da história local e à ampliação de suas percepções sobre História. 
Caracterizado como atividade de pesquisa e extensão, o projeto apresentava entre seus objetivos o intento de investigar os modos de vida da comunidade tradicional de Ponta Grossa, localizada no litoral leste do Estado do Ceará, no Município de Icapuí. Dentro desta abordagem, interessou perceber como se constituíram os saberes tradicionais sobre a pesca e as memórias sociais, assim como os relatos sobre a formação da comunidade. Por meio das narrativas, buscávamos entender todo o universo de valores, saberes e práticas cotidianas que conformavam os referenciais identitários da cultura local, além das temporalidades da memória que submergiam.

A partir da observação participativa e dos procedimentos da história oral, a constituição de um Acervo de Memórias da cultura local foi se delineando em diálogo com a comunidade. As demandas e interesses em torno da preservação do patrimônio ambiental e arqueológico - carentes de uma gestão preservacionista mais sistemática, ainda que as dunas e o sítio arqueológico de Ponta Grossa estejam inseridos nas Áreas de Proteção Ambiental (APA) colocada em perspectiva com os anseios de uma política de desenvolvimento de turismo sustentável pela população, convergiram para a necessidade de devolvermos as nossas pesquisas de registro das memórias e identidades da comunidade em um acervo virtual. Era de interesse nosso e da comunidade que este acervo de fontes orais e audiovisual em formato home page ou $C D$ rom integrasse posteriormente o Centro de Memória da sede da Associação de Turismo ou o museu comunitário em projeção.

Para a realização da produção dos registros e a constituição do Acervo de Memórias, foram realizadas quatro viagens de campo a Ponta Grossa. Antes, realizou-se um cronograma de leituras e discussões em torno dos métodos a serem utilizados. ${ }^{21}$ Ainda como embasamento do projeto e parte dos preparativos das viagens e dos bolsistas, foram levantados e discutidos outros trabalhos de caráter teórico e metodológico e pesquisas que versavam sobre a temática da memória, identidade, patrimônio cultural, comunidades marítimas, turismo e história local.

Também foram elaborados e discutidos os roteiros geral e individual para as entrevistas, além do Termo de Concessão dos depoentes. A produção de tais roteiros buscava muito mais instrumentalizar os bolsistas, uma vez que buscávamos respeitar a dinâmica própria de construção da narrativa pelo entrevistado em sua relação com o entrevistador. A opção pelo registro audiovisual, inclusive, caminhou nesta direção.

Entendendo que a memória é sempre uma reelaboração social e culturalmente determinada, interessava identificar e problematizar os dispositivos pelos quais foram articulados determinados usos do passado em demandas ancoradas em um presente igualmente determinado. Dito de outra maneira: era preciso atentar que por trás do desejo e vontade de memória estava a própria necessidade de reatualizar o sentimento de identidade. 
No campo, as duas primeiras viagens foram marcadas pelo caráter antropológico. Nelas, os bolsistas puderam, a partir de seus focos de observações, construir seus relatos e identificar os futuros depoentes e as temáticas a serem aprofundadas. Nas outras duas viagens, colocou-se em prática os procedimentos da História Oral na realização de 13 entrevistas em registro audiovisual, acompanhadas da produção de fotografias e digitalização de documentos. A escolha dos entrevistados, de modo geral, foi norteada muito em função dos aspectos de organização social e do cotidiano da comunidade. O trabalho, a família, a religiosidade e os elementos referentes à organização espacial possibilitavam apreender a maneira pela qual se organizavam as relações sociais entre os moradores. Assim, foram entrevistados indivíduos de vários âmbitos, como artesãos, pescadores, marceneiros, proprietárias de pousada, comerciantes, professores e integrantes das associações locais.

No total, foram realizadas mais de 30 horas de entrevistas. Após avaliação das viagens e a produção de relatórios, iniciou-se o processo de transcrição das entrevistas. Novamente recorremos às técnicas e métodos da história oral com o objetivo de dar o tratamento adequado à produção das fontes orais transcritas com a elaboração da ficha de identificação e catalogação, assim como o acondicionamento das fontes audiovisuais e fotográficas em suporte digital. Como resultado deste exercício, os bolsistas organizaram uma Oficina intitulada "História, Memória e Patrimônio: Experiências com a comunidade tradicional de Ponta Grossa (Icapuí - CE)" a convite do PET de História da Universidade Vale do Acaraú-Sobral. Igualmente, os resultados parciais foram apresentados no III Seminário Internacional História e Historiografia. ${ }^{22}$

Com a mudança de tutoria, os trabalhos de transcrição foram retomados e finalizados, mas a constituição do Acervo de Memórias e sua devolução ainda não foram concretizados e devolvidos à comunidade em virtude do corte da verba de custeio do PET no anos de 2012 e 2013. Após a finalização dos trabalhos de transcrição das entrevistas, os bolsistas fizeram um primeiro exercício de escrita que resultou em pequenos ensaios utilizando as narrativas dos moradores da comunidade de Ponta Grossa.

Ainda que a constituição do Acervo de Memórias não tenha sido efetivamente concretizada, a realização de todos os processos que envolveram a pesquisa e a produção das fontes orais e imagéticas pode ser avaliada como exitosa. Em experiência pioneira, os(as) alunos(as) da graduação puderam fazer uma imersão nos debates e desafios da historiografia contemporânea, além de refletirem e problematizarem, na prática, as técnicas e metodologias da pesquisa histórica em sintonia com as novas demandas do campo.

Nesse sentido, a iniciação à pesquisa e à extensão dilatou a percepção temporal e espacial dos discentes e contemplou o propósito de ampliação da aprendizagem e do desenvolvimento da consciência histórica. Ademais, possibilitou pensar e refletir sobre o significado do acervo no âmbito 
historiográfico para além de um espaço institucional físico e fechado que albergasse apenas documentos escritos. Dilatados dessa concepção tradicional de documento e mediante o diálogo com os estudos sobre memória, patrimônio e história oral, os(as) alunos(as) experimentaram a sensação de serem partícipes do próprio processo histórico de produção das fontes e do acervo de pesquisa.

\section{CONCLUSÃO}

Tomadas em conjunto e de forma retrospectiva, as experiências assinaladas apontam caminhos válidos, longe de regras, para a formação profissional do(a) historiador(a), ressaltando a possibilidade de (inter)relação entre pesquisa, ensino e extensão. Buscamos, portanto, indicar proposições alternativas a partir de experiências em acervos de pesquisa do Ceará e diante de problemas epistemológicos mais gerais do campo historiográfico, sobretudo na formação dos(as) alunos(as).

As reflexões mais gerais estiveram direta e indiretamente relacionadas a experiências que permitiram por em evidência o pensar sobre a iniciação à pesquisa. Contudo, longe de propormos caminhos fechados, buscamos entender esse "pensar" como forma de problematizar, a exemplo das considerações aventadas por José Carlos Reis, para quem o "pensar é perguntar continuamente, transformando possíveis soluções em novos enigmas". ${ }^{23}$ Afinal, o modo de proceder junto aos acervos no Ceará ou em qualquer outro lugar do mundo é histórico e, portanto, passível de alterações e contingências.

Nesse sentido, observamos que as ações planejadas junto aos acervos podem auxiliar em questões próprias ao trabalho do(a) historiador(a), tal como a busca incessante pela transposição da barreira temporal do presente através de vestígios documentais. Nas relações estabelecidas com o passado através dos indícios, mudou-se o pensar historicamente dos envolvidos, bem como suas noções de tempo e de espaço. E na busca por construir e alterar o entendimento sobre os tempos pretéritos, a iniciação à pesquisa em acervos alterou o próprio presente desses(as) estudantes.

Enfim, os trabalhos assinalados que podem ser tomados para reflexão por outros(as) historiadores(as) para além do Ceará permitiram o desenvolvimento de outras ações e relações com o passado que não simplesmente aquelas esvaziadas de sentido expressas na perda e na má conservação dos documentos nas instituições. O passado ornamentado, monumentalizado e contemplativo também foi posto sob a crítica dos discentes. Estimulados(as) a interrogar esses passados a partir do novo tempo presente dos acervos de pesquisa - uma temporalidade elaborada também por eles -, os estudantes diversificaram seus olhares e construíram problematizações sobre como as formas do tempo pretérito tocam as suas experiências de vida. 
Dessa maneira, as atividades de iniciação à pesquisa nos acervos permitiram refletir e problematizar referências comuns ao trabalho do historiador(a). Ao invés de partirmos das evidências para pensarmos as pesquisas, o exercício foi anterior e inverso. A preocupação se deu no sentido de pôr em destaque os locais e as formas (problemáticas) de disposição desses materiais, além das possibilidades de pesquisa relacionadas ao seu tratamento e até mesmo de sua construção. Dito de outra forma: aventar as possiblidades de aprendizagem e pesquisa com o tratamento e a problematização dos espaços que fazem a salvaguarda dos documentos, pondo em reflexão a função social dos acervos de pesquisa no Ceará.

Assim, buscamos mostrar como as reflexões sobre epistemologias práticas no âmbito da pesquisa histórica podem se relacionar com aspectos da arquivística e das ciências da informação, além de levarem a questões epistemológicas relacionadas à teoria da história, à história como disciplina $\mathrm{e}$ campo de saber, desdobrando-se, inclusive, em atividades de ensino e extensão. Nesse sentido, as propostas de observação de trabalho prático, tais como descrição, organização e produção, trouxeram questões de cunho filosófico para pensarmos a escrita da história e, também, a história como conhecimento.

Em suma, a alteração da linha do horizonte de percepção e da consciência histórica dos(as) envolvidos(as) no trabalho com acervos mostra como essas atividades podem ser positivas na iniciação e na formação dos discentes. Assim, antes da interpretação dos indícios, sugerimos que um caminho válido na aprendizagem do(a) aluno(a) para a aquisição de competências e habilidades no âmbito historiográfico seja aquele que passa pela reflexão e atuação planejada sobre as formas de identificação, organização e até mesmo produção das evidências utilizadas pelo(a) historiador(a). Afinal, se o presente sempre reinterpreta o passado, o presente também altera os acervos, ou melhor, as formas de acesso a esse passado. E esta deve ser uma preocupação concernente aos historiadores e historiadoras.

\section{NOTAS}

1 Cf. RUSEN, Jorn. Reconstrução do passado. Brasília: Editora da UnB, 2010. p. 104-105. REIS, José Carlos. História \& Teoria: historicismo, modernidade, temporalidade e verdade. Rio de Janeiro: FGV, 2006. ARÓSTEGUI, Julio. A pesquisa histórica: teoria e método. Bauru, SP: Edusc, 2006.

2 Ibidem.

3 Sobre uma visão panorâmica dos acervos de pesquisa no Ceará, destacamos aqui a obra de Cicinato Ferreira. Cf. FERREIRA NETO, Cicinato. A História do Ceará: fontes e bibliografia. Fortaleza: Premius, 2013.

4 Disponível em: <http://tribunadoceara.uol.com.br/blogs/apasseio/tag/orcamento/>. Acesso em: 20 abr. 2014. 
5 TAKEYA, Denise Monteiro. O capital mercantil estrangeiro no Brasil do século XIX: a atuação da Casa Boris Frères no Ceará. Revista de Ciências Sociais, Fortaleza, v. 15, n. 1, p. 111-145, 1994.

${ }^{6}$ Disponível em: <http://diariodonordeste.verdesmares.com.br/cadernos/opiniao/coluna/ ideias-1.205/materia-1.847203>. Acesso em: 20 abr. 2014.

7 RUSEN, op. cit., p. 476.

${ }^{8}$ Ibidem.

9 CERRI, Luís Fernando. Ensino de história e consciência histórica. Rio de Janeiro: FGV, 2011. p. 37-38.

${ }^{10}$ Índice da Saúde Pública 1836-1921 (Correspondendo a 12 caixas e 05 livros); Índice dos Ministérios 1822-1909 (Correspondendo a 122 livros); Índice de Leis e Resoluções Provinciais e Estaduais 1835-1928 (Correspondendo 11 caixas); Índica da Capitania do Ceará 1754-1866 (Correspondendo a 32 caixas); Índice da Escola dos Aprendizes Marinheiros 1886-1916 (Correspondendo a 01 caixa); Índice das Alfândegas de Aracati e Fortaleza 1836-1893 (Correspondendo 03 caixas); Índice das Câmaras Municipais 1700-1943 (Correspondendo a 99 caixas ); Índice da Ouvidoria Geral e Corregedoria da Comarca do Ceará 1778-1832 (Correspondendo a 05 caixas); Índice da Secretaria de Polícia - Rol dos culpados 19131940 (Correspondendo a 15 livros); Índice Guia de Fontes da Polícia do Ceará 1889-1954 (Correspondendo a 131 caixas); Índice das Estradas de Ferro de Baturité e Sobral/ Estrada de Rodagem de Sobral 1872-1918 (Correspondendo a 03 caixas e 04 livros ); Índice dos Açudes e Irrigação 1844-1918 (Correspondendo a 05 caixas); Índice de Localização da Hospedaria Geral de Emigração 1888-1915 (Correspondendo a 11 caixas); Índice da Assembleia Legislativa do Ceará 1844-1922 (Correspondendo a 03 caixas); Índice da Secretaria da Agricultura 1930-1935 (Correspondendo a 06 livros); Índice das Obras Públicas 1852-1933 (Correspondendo a 22 caixas); Índice do Grupo Arquivo Público e Museu Histórico 1932-1958 (Correspondendo a 10 caixas); Índice da Instrução Pública 1841-1895 (Correspondendo a 74 caixas e 79 livros); Índice da Comissão de Socorros Públicos 1862-1890 (Correspondendo 24 caixas); Índice dos Decretos 1890-1932 (Correspondendo 06 caixas e 22 livros); Índice da Fazenda Provincial 1835-1889 (Correspondendo a 23 caixas e 02 livros); Índice do Governo da Província do Ceará 1823-1889 (Correspondendo a 250 livros); Índice do Palácio Episcopal do Ceará- Bispado Cearense 18331916 (Correspondendo a 05 caixas); Índice dos Consulados 1889-1933 (Correspondendo 02 caixas); Índice da Secretaria da Agricultura - Colônia Cristina 1855-1921 (Correspondendo a 02 caixas e 15 livros); Índice da Junta Classificadora de Escravos 1882-1884 (Correspondendo a 03 caixas); Índice da Guarda Nacional 1850-1886 (Correspondendo a 37 caixas e 42 livros); Índice das Atas de eleições TRE-CE 1906-1924-1928-1930 (Correspondendo a 11 caixas); Índice da Inscrição de Eleitores TRE-CE 1932-1937 (Correspondendo a 111 livros); Guia das Obras Públicas 1852-1833 (Correspondendo a 9.626); Guia da Instrução Pública 1833-1889 (Correspondendo a 32.000 documentos). Disponível em: $<$ http://www.secult.ce.gov.br/index. php/equipamentos-culturais/arquivo-publico $>$. Acesso em: 25 mar. 2014.

${ }^{11}$ SECRETO, Verônica; TOLEDO, Edilene; RIBARD, Franck; VIANA JÚNIOR, Mário Martins. A história em processo: ações criminais em Fortaleza (1910-1950). Fortaleza: Expressão Gráfica, 2006.

${ }^{12}$ RUSEN, op. cit., p. 104-105.

${ }^{13}$ SOUSA, Mariana. "Terra da Luz": a abolição da escravidão no Ceará a partir do discurso político (1870-1880). Dissertação (Mestrado em História) - Universidade Estadual do Rio de Janeiro, Rio de Janeiro, 2014. 
${ }^{14}$ VIANA JÚNIOR, Mário Martins. As mulheres na expansão material de Fortaleza nos anos de 1920 e 1930. Dissertação (Mestrado em História Social) - Universidade Federal do Ceará, Fortaleza, 2009. p. 189-190.

${ }^{15}$ Ibidem.

${ }^{16}$ FORTALEZA, Lei no 9347 , de 11 de março de 2008. Diário Oficial do Município, Fortaleza, 01 abr. 2008, p. 2.

${ }^{17}$ REIS, op. cit.

${ }^{18}$ Contemplado no Edital Proext/2011.

${ }^{19}$ HARTOG, François. Evidência da história: o que os historiadores veem. Belo Horizonte: Autêntica, 2011.

${ }^{20}$ NOGUEIRA, Antonio Gilberto Ramos; SILVA FILHO, Antonio Luiz. Tempo, Patrimônio e Políticas de preservação no Brasil. In: NOGUEIRA, Antonio G. R.; SILVA FILHO, Antonio L. (Orgs.). História e Historiografia: perspectiva e abordagens. Recife: Editora Universitária UFPE, 2014.

${ }^{21}$ Cf. ALBERTI, Verena. Manual de História Oral. Rio de Janeiro: FGV, 2005. PORTELLI, Alessandro. Tentando aprender um pouquinho: algumas reflexões sobre a ética na História Oral. Projeto História, São Paulo, v. 15, abr. 1997; Projeto História, São Paulo, v. 14, p. 7-24, fev. 1997. O que faz a história oral diferente.

${ }^{22}$ Realizado em outubro de 2012, Fortaleza-CE. Disponível em: $<$ http://www.iiisihh.ufc.br/>. Acesso em: 20 abr. 2014.

${ }^{23}$ REIS, op. cit., p. 97.

\section{Artigo recebido em abril de 2014. Aceito em junho de 2014.}

